\title{
Overexpression of Bcl-2 enhances sensitivity of L929 cells to a lipophilic cationic photosensitiser
}

\section{Dear Editor,}

The protooncogene bcl-2 protects cells against apoptogenic insults, e.g., by preventing cytochrome $c$ release from mitochondria and activation of caspases. ${ }^{1}$ Overexpression of $\mathrm{Bcl}-2$, e.g., blocks tumour necrosis factor $\alpha$-mediated toxicity in mouse fibrosarcoid L929 cells. ${ }^{2}$ Carcinoma cells have an elevated mitochondrial transmembrane potential $(\Delta \Psi),{ }^{3}$ and are, therefore, sensitive to positively charged compounds that are taken up in response to $\Delta \Psi$. The reason for this increase in $\Delta \Psi$, its relation to cancer and resistance to apoptosis are not yet fully understood, however, this feature of tumour cells can be exploited therapeutically, i.e., by targeting them with cationic drugs. ${ }^{4}$ Photodynamic therapy kills cells by activation of a photosensitiser with light followed by generation of reactive oxygen species, and is used to treat a variety of dysplasias and superficial cancers. ${ }^{5}$ The physicochemical properties of a photosensitiser such as charge and hydrophobicity determine its intracellular localisation and primary site of damage after light exposure. We compared dark toxicity and light-induced toxicity of three photosensitisers (victoria blue BO, VB-BO; tetra ( $m$-hydroxyphenyl)chlorin, mTHPC; meso-tetra (4-sulfonatophenyl)porphine, TPPS 4 ) in a pair of L929 murine fibrosarcoma cell lines, one of which overexpresses $\mathrm{Bcl}-2$ and has elevated $\Delta \Psi^{2}$, and investigated the mode of cell death.

We first analyzed the localisation of the three photosensitisers in control (BV3) and Bcl-2 overexpressing cells (B22) by confocal laser scanning microscopy (excitation $568 \mathrm{~nm}$, emission $>590 \mathrm{~nm}$ ). The cationic lipophilic VB-BO accumulated in mitochondria, the neutral lipophilic mTHPC was detected in membranous structures, and the anionic hydrophilic TPPS 4 was localised in organelles resembling lysosomes (not shown). Localisation patterns were identical in both cell lines. Quantitative uptake of mTHPC and TPPS $_{4}$ into BV3 and B22 cells as measured by fluorescence intensity (excitation $530-595 \mathrm{~nm}$, emission $>615 \mathrm{~nm}$ ) was equal. B22 cells, however, took up $18 \%$ more VB-BO as compared to BV3 cells. VB-BO uptake depended on $\Delta \Psi$ since it was reduced to a great extent in the presence of a mitochondrial uncoupler.

Incubation of the cells for $4 \mathrm{~h}$ in the dark with 10 and $30 \mu \mathrm{M}$ VB-BO resulted in 1.6- and 3.3-fold lower surviving fraction of B22 than BV3 cells, respectively (Figure 1A, a). The B22 cells with an increase $\Delta \Psi$ also showed higher sensitivity when incubation with $1 \mu \mathrm{M}$ of the dye was followed by illumination with white light of 400 to $780 \mathrm{~nm}$ (Figure 1A,b). No statistically significant differences between BV3 and B22 cells were found for dark toxicity and light-induced toxicity of the uncharged mTHPC (Figure 1B, a and b). TPPS 4 was not toxic up to $0.3 \mathrm{mM}$ and was equally toxic to both cell lines at $1 \mathrm{mM}$ in the dark (Figure $1 C, a)$. The surviving fraction of BV3 cells was lower than that of B22 cells when incubation with TPPS $_{4}$ was followed by illumination (Figure 1C, b). Illumination of the cells in the absence of a photosensitiser had no effect on survival. Figure 1D shows cytochrome $c$ release into the cytosol $1 \mathrm{~h}$ after incubation of the cells with photosensitisers and illumination. Cytochrome $c$ release in B22 was more pronounced after incubation with VB-BO and illumination as compared to BV3 cells in accordance with the higher light-induced toxicity of VB-BO in B22 than in BV3 cells. In contrast, incubation with mTHPC or TPPS ${ }_{4}$ and illumination induced equal cytochrome $c$ release in B22 and BV3 cells. After incubation with the photosensitisers and illumination, cells were stained with annexin $\mathrm{V}$ and propidium iodide. Untreated cells grown on cover slips had an elongated shape and poorly bound annexin $\mathrm{V}$ as determined by confocal laser scanning microscopy (not shown). Thirty minutes after illumination in the presence of any of the three photosensitisers, cells showed extensive membrane blebbing, rounding off and increased annexin $\mathrm{V}$ binding in the absence of propidium iodide staining, indicators of apoptosis (not shown).

From previous reports it is known that overexpression of $\mathrm{Bcl}-2$ or $\mathrm{Bcl}-\mathrm{X}_{\mathrm{L}}$ protects cells against photodynamic therapy. ${ }^{6}$ Here we show that, depending on the photosensitiser used, $\mathrm{Bcl}-2$ overexpression has a positive, none, or even a negative effect on survival of cells after in vitro photodynamic therapy. Cells die via necrosis or apoptosis, depending on the photosensitiser, cell type and treatment protocol. ${ }^{7}$ When mitochondria are the subcellular target, photodynamic therapy induces apoptosis, ${ }^{8}$ but for lysosomal targeting contradictory results were reported. We investigated cytochrome $c$ release from mitochondria (Figure 1D), a hallmark of apoptosis known to occur after photodynamic therapy. Further studies are required to investigate later steps in the apoptotic programme, e.g., caspase activity and PARP cleavage, and the possible inhibitory function of Bcl-2. The B22 cells are used here as a model for cancer cells with which they share two characteristics: they are protected against apoptosis, and they show higher $\Delta \Psi$ as compared to normal cells, ${ }^{2}$ or BV3 cells in this study. Lipophilic cationic drugs, e.g., VB-BO, accumulate in response to $\Delta \Psi$ preferentially in tumour cells and may display high toxicity despite the increased resistance of the cells to other stress factors. It remains to be investigated whether this promising approach is also a successful strategy for targeting and killing cancer cells in vivo. 
A

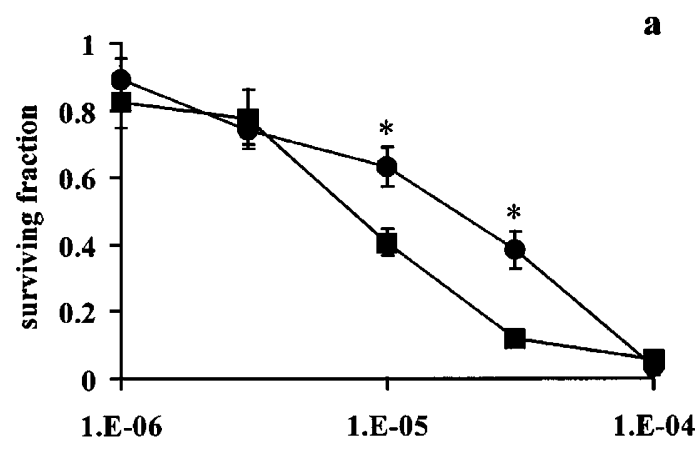

VB-BO concentration (M)

B

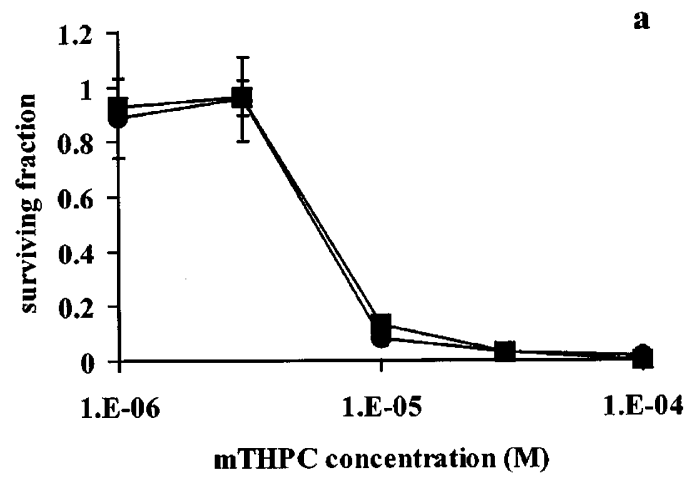

C

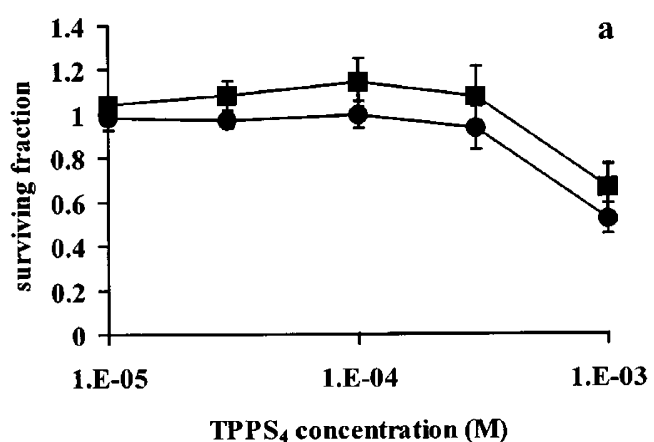

D

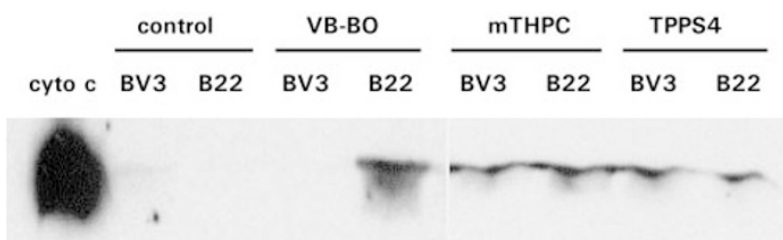

b

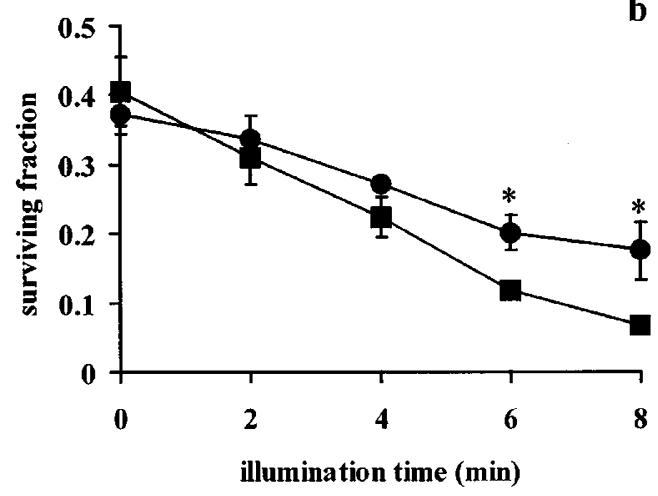

b

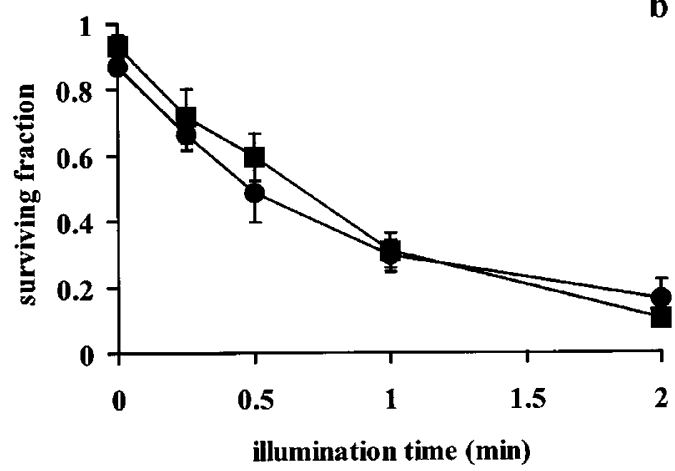

b

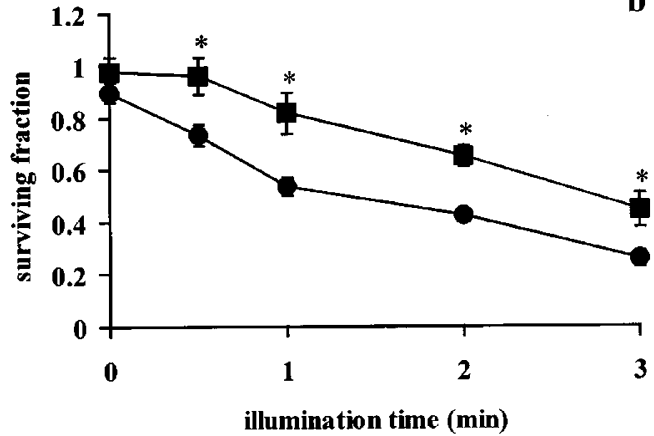

illumination time (min)

Figure 1 Toxicity of VB-BO $(\mathbf{A}), \mathrm{mTHPC}_{(\mathbf{B}) \text { and TPPS }}(\mathbf{C})$ in BV3 and B22 cells. Cells were incubated with the indicated concentrations of the photosensitisers for $4 \mathrm{~h}$ (VB-BO: A, a) or $24 \mathrm{~h}$ (mTHPC: B, a; TPPS 4 : C, a) in the dark or with $1 \mu \mathrm{M}$ VB-BO (A, b), $0.1 \mu \mathrm{M} \mathrm{mTHPC} \mathrm{(B,} \mathrm{b)} \mathrm{or} 10 \mu \mathrm{M} \mathrm{TPPS}$ (C, b) followed by illumination with an Intralux ${ }^{\mathbb{R}}$ MDR 100 lamp (Volpi AG, Schlieren, Switzerland) equipped with a $100 \mathrm{~W}$ xenon lamp emitting at $400-780 \mathrm{~nm}$ (power density at $555 \mathrm{~nm}$ was $60.4 \mathrm{~mW} / \mathrm{cm}^{2}, 1 \mathrm{~min}$ illumination corresponds to $3.6 \mathrm{~J} / \mathrm{cm}^{2}$ ). Cell survival was determined by MTT assay. BV3 cells, B22 cells, "statistically significant difference (BV3 vs B22, $\alpha=0.05$, Wilcoxon-Mann-Whitney test. (D) Cytochrome $c$ release $1 \mathrm{~h}$ after incubation of cells with photosensitisers and illumination detected by Western blot. BV3 and B22 cells were incubated with $1 \mu \mathrm{M}$ VB-BO for $1 \mathrm{~h}$ and illuminated for $8 \mathrm{~min}$ (VB-BO), with $0.1 \mu \mathrm{M} \mathrm{mTHPC}$ for $24 \mathrm{~h}$ and illuminated for $2 \mathrm{~min}$ (mTHPC), or with $10 \mu \mathrm{M} \mathrm{TPPS}$ for $24 \mathrm{~h}$ and illuminated for $5 \mathrm{~min}\left(\right.$ TPPS $\left._{4}\right)$. Control cells were neither incubated with a photosensitiser nor illuminated 
Financial support by Leica and Avina Foundation, the Baugarten Foundation and the Kantonale Zürcherische Krebsliga is gratefully acknowledged. B22 and BV3 cells were kindly provided by E Peterhans.

\section{SD Klein ${ }^{1,2}, H$ Walt ${ }^{1}, S$ Rocha ${ }^{3}, P$ Ghafourifar ${ }^{2}, M$ Pruschy $^{3}$,} KH Winterhalter ${ }^{2}$ and $C$ Richter,2

${ }^{1}$ Research Division of Gynaecology, Department of Gynaecology and Obstet-rics, University Hospital, Zurich, Switzerland; ${ }^{2}$ Institute of Biochemistry, Swiss Federal Institute of Technology, Zurich,

Switzerland; ${ }^{3}$ Department of Radiation Oncology, University Hospital, Zurich, Switzerland.

*Corresponding author: C Richter, Institute of Biochemistry, Swiss Federal Institute of Technology, $\mathrm{CH}-8092$ Zurich, Switzerland.

Tel: +41-1-6323136; Fax +41-1-6321121;

E-mail: richter@bc.biol.ethz.ch
1. Kluck RM et al. (1997) Science 275: 1132-1136

2. Hennet T et al. (1993) Cancer Res. 53: 1456-1460

3. Nadakavukaren KK et al. (1985) Cancer Res. 45: 6093-6099

4. Koya K et al. (1996) Cancer Res. 56: 538-543

5. Fisher AMR et al. (1995) Lasers Surg. Med. 17: 2-31

6. He J et al. (1996). Photochem. Photobiol. 64: 845-852

7. Dellinger M (1996) Photochem. Photobiol. 64: 182-187

8. Ball DJ et al. (1998) J. Photochem. Photobiol. B. 42: 159-163. 